\title{
Common Contact Sensitizers among Patients with Hand Eczema: A Multicenter-Study in Nepal
}

\author{
Bhattarai S', Rijal A², Agrawal S
}

${ }^{1}$ Associate Professor, Department of Dermatology and Venereology, Kathmandu Medical College and Teaching Hospital, Sinamangal, Nepal, ${ }^{2}$ Professor, Department of Dermatology and Venereology, B. P. Koirala Institute of Health Sciences, Dharan, Nepal, ${ }^{3}$ Professor and Head, Department of Dermatology and Venereology, B. P. Koirala Institute of Health Sciences, Dharan, Nepal.

\begin{abstract}
Introduction: Allergic contact dermatitis in Nepal is not an uncommon disorder. Patch testing is a well established method of diagnosing allergic contact dermatitis. Patients with contact dermatitis are well known to have impaired quality of life which often leads to frequent dermatological consultations.

Objective: Lack of data from Nepal has prompted us to undertake this study with the aims to know the frequency of allergic contact dermatitis and the commonest contact allergens among the patients with Hand eczema attending the out-patient department of dermatology, B.P. Koirala Institute of Health Sciences and Kathmandu Medical College Teaching Hospital.

Material and Methods: A total of 256 patients were included in the study. Out of them 195 with hand eczema agreed to participate and undergo patch testing. The antigens used included the Indian standard series of patch test allergens approved by Contact and Occupational Dermatoses Forum of India.

Results: Hundred and ten cases (56.4\%) were patch test positive (PTP) at 48 as well as 96 hours to at least one allergen. PTP was seen more commonly in females. The most common allergen in females was nickel sulphate followed by cobalt chloride, gentamicin and mercapto mix while males were positive to potassium dichromate, followed by epoxy resin, fragrance mix and nickel sulphate.

Conclusion: Patch testing has proved a useful tool for the detection of allergic contact dermatitis and for identification of contact allergens. When positive reactions correlate with environmental exposure the test usually assists the physician in establishing the cause of dermatitis, hence treating the patients and improving their quality of life.

Key words: Hand Eczema, Contact Allergen, Patch test
\end{abstract}

\section{Introduction}

T he term hand eczema (HE) implies when the dermatitis is largely confined to the hands with only minor involvement of the other areas. The condition has been described as a chronic disabling and distressing condition both for the physicians and patients alike. The reported prevalence of $\mathrm{HE}$ in the general population is estimated to be about $2-10 \%{ }^{1,2}$ and it accounts for $21-35 \%$ of all types of eczema. ${ }^{3}$

The pathogenesis of hand eczema is multifactorial, with contribution of internal factors such as an

Address for correspondence

Dr. Sabina Bhattarai

Associate Professor

Department of Dermatology and Venereology,

Kathmandu Medical College and Teaching Hospital,

Sinamangal, Nepal

E-mail: sabeenab@gmail.com atopic status and external factors, such as allergens and irritants. The precise impact of allergic contact dermatitis remains unclear, although patients often suspect an allergy and recently published guidelines stress the importance of patch testing. ${ }^{4,5}$

There are no standard series of patch test allergens in Nepal and our objective in this study is aimed at identifying common allergens responsible for allergic contact dermatitis among hand eczema patients in the general Nepalese population using the Indian Standard baseline series.

\section{Materials and Methods}

\section{Patients}

This was a hospital based descriptive study in which all clinically diagnosed cases of hand eczema attending the Dermatology Out Patient Department of B. P. 
Koirala Institute of Health Sciences, Dharan over May 2009 - June 2012 and the Out Patient Department July 2012-June 2015, Kathmandu Medical College, constituted the study population.

Other skin diseases involving the hand, such as infective dermatitis, dermatophytide, eczematous drug reactions, psoriasis and cumulative insult dermatitis were excluded by history and clinical examination.

A detailed history of each patient was recorded in the proforma designed for the study which was approved by the institutional review board and the ethical committee.

\section{Patch test}

Patch test was done in all patients of hand eczema using the Indian Standard Series of Allergens as approved by the Contact and Occupational Dermatoses Forum of India (CODFI), consisting of 28 allergens

Finn chambers were used and allergens, usually incorporated in petrolatum, were applied in round chambers of inert material (aluminum, polyethylene), which were mounted on adhesive tapes free from colophony.

Patch tests were applied on the upper half of the back after cleaning the area with spirit and the results were recorded at 48 hours and 96 hours.

Table 1: Frequency of positive patch test reactions $(n=110)$

\section{Statistical analysis}

Data was tabulated and interpreted in terms of percentage, mean and standard deviation in the computer using SPSS version 20 . To test the significance of association Chi square test was applied.

\section{Results}

Total 256 patients with hand eczema were approached. Out of them 195 agreed to participate in the study and took patch testing. Out of 195 patients, 117 were females and remaining 78 were males, for a gender ratio of 1.5:1. The mean age of the respondents was 32 years \pm 14.5 years. The age varied within a wide range of 15 years to 70 years. Duration of disease at the time of presentation of respondents was found to range from minimum 1 week to maximum 15 years. Out of 195 cases who had done patch testing, 110 cases (56.4\%) showed positive reaction in patch testing to at least one allergen.

Table 1 shows the common positive tested allergens in all patients with hand eczema. The most frequent sensitizer was Nickel sulphate (22.7\%). Subsequently, Gentamicin, Fragrance mix, Epoxy resin and Potassium dichromate caused a substantial amount of positive reactions.

Table 2 displays the distribution of positive patch test reaction by sex. Females had more sensitizer for Nickel, and Gentamicin whereas males had more sensitizer for Fragrance mix, Epoxy resin and Potassium dichromate but these were not statistically significant. Overall, the most frequent sensitizer did not deviate between the two study centers.

\begin{tabular}{|l|c|c|}
\hline Allergen & No of Patients (\%) & 95\% Confidence Interval (\%) \\
\hline Nickel sulphate & $25(22.7)$ & $31.1-18.9$ \\
\hline Gentamicin & $17(15.5)$ & $22.3-11.7$ \\
\hline Fragrance mix & $16(14.5)$ & $21.1-10.9$ \\
\hline Epoxy resin & $14(12.7)$ & $18.9-9.1$ \\
\hline Potassium dichromate & $12(11.0)$ & $16.6-7.4$ \\
\hline Cobalt chloride & $8(7.3)$ & $11.8-4.2$ \\
\hline Neomoycin sulphate & $3(2.7)$ & $5.4-0.6$ \\
\hline Parabens & $3(2.7)$ & $5.4-0.6$ \\
\hline Formaldehyde & $2(1.8)$ & $4.0-0.03$ \\
\hline Mercapto mix & $3(2.7)$ & $5.4-0.6$ \\
\hline Balsam of peru & $3(2.7)$ & $5.4-0.6$ \\
\hline Nitrofurazone & $4(3.6)$ & $6.8-1.2$ \\
\hline
\end{tabular}


Table 2: Gender-wise distribution of patch positive cases $(n=110)$

\begin{tabular}{|l|c|c|}
\hline \multirow{2}{*}{ Allergen } & \multicolumn{2}{|c|}{ Gender-wise distribution of patch positive cases } \\
\cline { 2 - 3 } & Male (\%) & Female (\%) \\
\hline Nickel sulphate & $10(20.4)$ & $15(24.6)$ \\
\hline Gentamicin & $6(12.2)$ & $11(18.0)$ \\
\hline Fragrance mix & $10(20.4)$ & $6(9.8)$ \\
\hline Epoxy resin & $9(18.4)$ & $5(8.2)$ \\
\hline Potassium dichromate & $8(16.3)$ & $4(6.6)$ \\
\hline Cobalt chloride & $2(4.1)$ & $6(19.8)$ \\
\hline Neomoycin sulphate & $1(2.0)$ & $2(3.3)$ \\
\hline Parabens & $1(2.0)$ & $2(3.3)$ \\
\hline Formaldehyde & 0 & $2(3.3)$ \\
\hline Mercapto mix & $1(2.0)$ & $2(3.3)$ \\
\hline Balsam of peru & 0 & $3(4.9)$ \\
\hline Nitrofurazone & $1(2.0)$ & $3(4.9)$. \\
\hline Total & $\mathbf{4 9 ( 4 4 . 5 )}$ & $\mathbf{6 1}(\mathbf{5 5 . 5})$ \\
\hline
\end{tabular}

\section{Discussion}

An estimated $2-10 \%$ of population is likely to develop hand eczema at some point of time during life. In addition, $20-35 \%$ of all dermatitis affects the hands. It appears to be the most common occupational skin disease, comprising 9-35\% of all occupational disease and up to $80 \%$ or more of all occupational contact dermatitis. $^{7}$

The aetiology of hand eczema is a complex combined effect of major causes and other factors, where the degree of influence of each factor is impossible to determine. The most common cause however still appears to be the exogenous cause.

Allergic contact sensitization is known to be influenced by environmental, cultural, occupational, individual, genetic and racial or ethnic factors. Patch Testing has been proven to establish a positive role in identifying the contact allergens in hand eczema patients suspected of having an allergic etiology. Our study showed 110 cases (56.4\%) with patch test positivity which is similar to the previous studies found in the literature ranging from $40-70 \%{ }^{7-12}$

Nickel is a well-known sensitizer and various efforts have been made to reduce the number of sensitizations in the general population. Our study found nickel as the most frequent contact sensitizer in $22.7 \%$ patients which was comparable to other studies. ${ }^{12-15}$ Nickel positivity has shown a female preponderance in our study as reported by Bilcha et al ${ }^{15}$ and Bilcha et al ${ }^{16}$. The higher rates of positive patch test reactions for nickel sulfate in females could relate to their ear piercing, cosmetic application and ornament use behavior.

Gentamicin was the next common sensitizer seen in our patients $(15.5 \%)$ with a similar female preponderance. This could be explained by the setting of the study population where female nurses coming for visits were more frequent and the easy availaibility of the medication for minor skin lesions.

The third, fourth and the fifth common antigen in our study was found to be in fragrance mix in 16 (14.5\%), epoxy resin $14(12.7 \%)$ and potassium dichromate in $12(11.0 \%)$ patients respectively with a slightly higher male preponderance. Construction work is one among the most important occupations predisposing to allergic contact dermatitis ${ }^{17}$ and is most commonly because of potassium dichromate. ${ }^{18,19}$ This is shown in our study by higher rates of positive reactions to potassium dichromate in cement workers and in subjects with hand dermatitis as reported in the literature. ${ }^{20}$

\section{Conclusions}

Nickel, Gentamicin, Fragrance mix, Epoxy resin and Potassium dichromate are common sensitizers in patients with Hand eczema in Nepal. Thus, the identification and evaluation of risk factors for the development and persistence of hand eczema are important to prevent the morbidity of patients and to improve their quality of life. 


\section{References}

1. Thyssen JP, Johansen JD, Linneberg A, Menné T. The epidemiology of hand eczema in the general population-prevalence and main findings. Contact Dermatitis 2010; 62: 75-87. http:// dx.doi.org/10.1111/j.1600-0536.2009.01669.x

2. Meding B, Jarvholm B. Hand eczema in Swedish adults: Changes in prevalence between 1983 and 1996. J Invest Dermatol 2002; 118: 719-23. http://dx.doi.org/10.1046/j.15231747.2002.01718.x

3. Clark RAF, Hopkins TT. The other eczemas. In: Moschella SL, Hurley HJ, editors, Dermatology $3^{\text {rd }}$ Ed Vol 1 Philadelphia, WB Saunders Company, 1993: 493-8.

4. Menné T, Johansen JD, Sommerlund $M$, Veien NK, Danish Contact Dermatitis Group. Hand eczema guidelines based on the Danish guidelines for the diagnosis and treatment of hand eczema. Contact Dermatitis 2011; 65: 3-12. http://dx.doi. org/10.1111/j.1600-0536.2011.01915.x

5. Diepgen $\mathrm{TL}$, Elsner $\mathrm{P}$, Schliemann $\mathrm{S}$, Fartasch M, Köllner A, Sudlik C, et al. Guideline on the management of hand eczema ICD-10 Code: L20. L23. L24. L25. L30. J Dtsch Dermatol Ges 2009; 7(Suppl 3): S1-S16. http://dx.doi.org /10.1111/j.1610-0379.2009.07061_supp.x

6. Elston DM, Ahmed DD, Watsky $\mathrm{KL}$, Schwarzenberger K. Hand dermatitis. J Am Acad Dermatol 2002; 47: 291-9. http://dx.doi. org/10.1067/mjd.2002.122757

7. Francalanci $S$, Giorgini S, Ricci L, Achille S. Patch testing by additional series of allergens: results of further experiences. Am J Contact Dermat 2001; 12: 203-7. http://dx.doi.org/10.1053/ ajcd.2001.29550

8. Menn'e T, Dooms-Goossens A, Wahlberg JE, White IR and Shaw S. How large a proportion of contact sensitivities are diagnosed with the European standard series? Contact Dermatitis 1992; 26: 201-2. http://dx.doi. org/10.1111/j.1600-0536.1992.tb00299.x

9. Al-Sheikh O A, Gad El-Rab MO. Allergic contact dermatitis: clinical features and profile of sensitizing allergens in Riyadh, Saudi Arabia. Int J Dermatol 1996; 35: 493-7. http://dx.doi. org/10.1111/j.1365-4362.1996.tb01664.x

10. Bajaj A K, Saraswat A, Mukhija G, Rastogi $S$, Yadav $S$. Patch testing experience with 1000 patients. Indian J Dermatol Venereol
Leprosy 2007; 73: 313-8. http://dx.doi. org/10.4103/0378-6323.34008

11. Akyol A, Boyvat A, Peksari Y, Gurgey E. Contact sensitivity to standard series allergens in 1038 patients with contact dermatitis in Turkey. Contact Dermatitis 2005; 52: 333-7. http:// dx.doi.org/10.1111/j.0105-1873.2005.00608.x

12. Bhattarai S, Agrawal S, Rijal A. Clinical and Contact Allergological Observations on Hand Eczema: A Descriptive Study. Nepal Med Coll J 2013; 15: 189-92.

13. Boonstra MB, Christoffers WA, Coenraads PJ, Schuttelaar MLA. Patch test results of hand eczema patients: relation to clinical types. J Eur Acad Dermatol Venereol 2015; 29: 940-7. http://dx.doi.org/10.1111/jdv.12735

14. Agarwal US, Besarwal RK, Gupta R, Agarwal $P$, Napalia S. Hand eczema. Indian J Dermatol 2014; 59: 213-24. http://dx.doi.org/10.4103/00195154.131372

15. Bilcha KD, Shibeshi D, Grangsjo A. Patch test reaction on Ethiopian subjects with eczema. International Journal Dermatology 2009; 48: 979-83. http://dx.doi.org/10.1111/j.13654632.2009.04070.x

16. Bilcha KD, Ayele A, Shibeshi D, Lovell C. Patch testing and contact allergens in Ethiopia-results of 514 contact Dermatitis patients using the European baseline series. Contact Dermatitis 2010; 63: 140-5. http://dx.doi.org/10.1111/ j.1600-0536.2010.01740.x

17. Rietschel R L, Mathias C G T, Joseph F, Pratt M, Taylor JS, Sherertz EF et al. Relationship of occupation to contact dermatitis: evaluation in patients tested from 1998 to 2000 . Am J Contact Dermat 2002; 13: 170-6. http://dx.doi. org/10.1053/ajcd.2002.36635

18. Macedo M S, de Avelar Alchorne A O, Costa E B, Montesano F T. Contact allergy in male construction workers in Sao Paulo, Brazil, 2000-2005. Contact Dermatitis 2007; 56: 232-4. http://dx.doi.org/10.1111/j.16000536.2007.01085.x

19. Uter W, Ruhl R, Pfahlberg A Geier J, Schnuch $A$, Gefeller $O$ et al. Contact allergy in construction workers: results of a multifactorial analysis. Ann Occup Hyg 2004; 48: 21-7. http:// dx.doi.org/10.1093/annhyg/meg080

20. Lakshmi C, Srinivas C R. Hand eczema: An update. Indian J Dermatol Venereol Leprol 2012; 78: 569-82. http://dx.doi.org/10.4103/03786323.100547 